\title{
Factors contributing to sex differences in functional outcomes and participation after stroke
}

\author{
Hoang T. Phan, MD, Christopher L. Blizzard, PhD, Mathew J. Reeves, PhD, Amanda G. Thrift, PhD, \\ Dominique A. Cadilhac, PhD, Jonathan Sturm, PhD, Emma Heeley, PhD, Petr Otahal, GDipSc, \\ Konstantinos Vemmos, PhD, Craig Anderson, PhD, Priya Parmar, PhD, Rita Krishnamurthi, PhD, \\ Suzanne Barker-Collo, PhD, Valery Feigin, PhD, Yannick Bejot, MD, Norberto Luiz Cabral, PhD, \\ Antonio Carolei, PhD, Simona Sacco, PhD, Nicolas Chausson, PhD, Stephane Olindo, PhD, Peter Rothwell, PhD, \\ Carolina Silva, PhD, Manuel Correia, PhD, Rui Magalhães, PhD, Peter Appelros, PhD, Janika Kõrv, PhD, \\ Riina Vibo, PhD, Cesar Minelli, MD, and Seana L. Gall, PhD
}

Neurology ${ }^{\circledR}$ 2018;90:e1945-e1953. doi:10.1212/WNL.0000000000005602

\section{Abstract}

\section{Objective}

To examine factors contributing to the sex differences in functional outcomes and participation restriction after stroke.

\section{Methods}

Individual participant data on long-term functional outcome or participation restriction (i.e., handicap) were obtained from 11 stroke incidence studies (1993-2014). Multivariable logbinomial regression was used to estimate the female:male relative risk (RR) of poor functional outcome (modified Rankin Scale score $>2$ or Barthel Index score $<20$ ) at 1 year $(10$ studies, $\mathrm{n}=$ 4,852 ) and 5 years $(7$ studies, $n=2,226)$. Multivariable linear regression was used to compare the mean difference $(\mathrm{MD})$ in participation restriction by use of the London Handicap Scale (range 0-100 with lower scores indicating poorer outcome) for women compared to men at 5 years ( 2 studies, $\mathrm{n}=$ 617). For each outcome, study-specific estimates adjusted for confounding factors (e.g., sociodemographics, stroke-related factors) were combined with the use of random-effects meta-analysis.

\section{Results}

In unadjusted analyses, women experienced worse functional outcomes after stroke than men (1 year: pooled $\mathrm{RR}_{\text {unadjusted }} 1.32,95 \%$ confidence interval $[\mathrm{CI}] 1.18-1.48 ; 5$ years: $\mathrm{RR}_{\text {unadjusted }} 1.31$, 95\% CI 1.16-1.47). However, this difference was greatly attenuated after adjustment for age, prestroke dependency, and stroke severity (1 year: $\mathrm{RR}_{\text {adjusted }} 1.08$, 95\% CI 0.97-1.20; 5 years: $\mathrm{RR}_{\text {adjusted }} 1.05,95 \% \mathrm{CI}$ 0.94-1.18). Women also had greater participation restriction than men (pooled $\mathrm{MD}_{\text {unadjusted }}-5.55,95 \% \mathrm{CI}-8.47$ to -2.63 ), but this difference was again attenuated after adjustment for the aforementioned factors $\left(\mathrm{MD}_{\text {adjusted }}-2.48,95 \% \mathrm{CI}-4.99\right.$ to 0.03$)$.

\section{Conclusions}

Worse outcomes after stroke among women were explained mostly by age, stroke severity, and prestroke dependency, suggesting these potential targets to improve the outcomes after stroke in women.

\author{
Correspondence \\ Dr. Gall \\ Seana.Gall@utas.edu.au
}

RELATED ARTICLE

Editorial

Sex differences in stroke outcomes: A case for better health care for older women

Page 995 


\section{Glossary}

$\mathbf{B I}=$ Barthel Index; $\mathbf{C I}=$ confidence interval; INSTRUCT = International Stroke Outcomes Study; IPD = individual participant data; $\mathbf{L H S}=$ London Handicap Scale; $\mathbf{M D}=$ mean difference; $\mathbf{m R S}=$ modified Rankin Scale; $\mathbf{R R}=$ relative risk.

It is not often recognized that the burden of stroke falls more heavily on women than men. ${ }^{1}$ Women appear to experience worse functional outcomes than men after stroke, meaning they are more often restricted in activities of daily living ${ }^{2}$ and are more likely to require supported care. ${ }^{3}$ There is also evidence that women experience greater participation restriction (or handicap) — reflecting the influence of functional loss on a person's social, economic, and recreational activities-compared to men after stroke. ${ }^{4}$ Participation restriction is rarely measured in stroke outcomes research, although it is a person-centered outcome that is important to survivors of stroke ${ }^{5}$ and can greatly affect stroke survivor's health-related quality of life. ${ }^{6}$

It is important not only to document sex differences in functional outcomes and participation restriction but also to understand what accounts for these differences to inform interventions to address these disparities. ${ }^{7}$ The causes of differences between women and men in these outcomes have not been conclusively determined in either short- or longterm studies after stroke, ${ }^{4,8}$ partly because there have been few well-conducted studies designed to examine the etiology of sex differences in stroke outcomes. Many studies have been based on hospital or convenience samples for which selection bias may adversely affect conclusions. Existing research has often reported the associations between sex and outcomes as incidental findings in multivariable models (e.g., using stepwise regression) with considerable variation in outcome measurement and adjustment for covariates.

We established our collaboration to examine sex differences in stroke outcomes from pooled data obtained from only highquality population-based studies with long-term follow-up of outcomes. ${ }^{9}$ Our aims were to quantify the sex differences in functional outcome and participation restriction in the long term after stroke and to identify the factors that contribute to these disparities.

\section{Methods}

The International Stroke Outcomes Study (INSTRUCT) is a collaboration of investigators from 13 gold standard population-based stroke incidence studies from Australasia, Europe, South America, and the Caribbean. ${ }^{9}$ The 13 included studies in the INSTRUCT represented 59\% of the 22 potentially eligible studies later identified by systematic search (appendix e-1, links.lww.com/WNL/A488, figure e-1, links. lww.com/WNL/A489, and table e-1, links.lww.com/WNL/ A490). The INSTRUCT, an individual participant data (IPD) meta-analysis of long-term outcomes after stroke, was registered in PROSPERO ${ }^{10}$ and performed according to Preferred
Reporting Items for Systematic Reviews and Meta-Analyses IPD guidelines. ${ }^{11}$ This study was approved by the Tasmanian Health and Medical Human Research Ethics Committee (H0014861). All of the participating studies had signed informed consent and approval from their respective local ethics committees. Among the 13 studies included in INSTRUCT, 11 had measures of functional outcome or participation restriction collected up to 5 years after stroke.

\section{Outcome measurement}

In 9 studies, participants were followed up with face-to-face interviews conducted at 1 and 5 years after stroke, while in 2 studies (Joinville, Tartu), mail or telephone interviews were used (table e-2, links.lww.com/WNL/A490).

Measures of functional outcome included the Barthel Index (BI) and modified Rankin Scale (mRS; table 1). The 20-point version of BI was used in 2 studies (Matão, Melbourne). The $\mathrm{mRS}$, with a score ranging from 0 (no) to 5 (severe disability), was used in the remaining studies. Poor outcome was defined as an mRS score $>2{ }^{12}$ or BI score $<20{ }^{13}$

Two of the cohorts (Melbourne, Auckland) included assessment of participation restriction (see appendix e-2, links.lww. com/WNL/A488, for this terminology) at 5 years after stroke with the London Handicap Scale (LHS) ${ }^{14}$ The dimensions of the LHS include orientation, physical independence, mobility, occupation, social interaction, and economic self-efficiency. The overall LHS score, obtained by applying weights to each subdomain score $(0=$ worst, $6=$ no disadvantage $)$, ranges from 0 (very disadvantaged) to 100 (not disadvantaged). ${ }^{14}$

\section{Predictors of outcome}

We obtained data on a wide range of factors that might contribute to sex differences based on our previous research. ${ }^{4}$ The availability and specification of individual variables differed between studies (appendix e-2, links.lww.com/WNL/A488). We grouped data into the following categories: (1) sociodemographics $(n=5$ variables), (2) prestroke health (dependence, comorbidities, health behaviors; $\mathrm{n}=14$ variables), (3) stroke-related factors (stroke type, stroke severity, year of stroke occurrence), (4) treatment and management ( $\mathrm{n}=14$ variables), and (5) poststroke factors (poststroke depression, stroke recurrence up to 5 years of follow-up). In general, these factors were from interviews conducted within a few days of the index event with patients and families, medical records, and/or physician consultation.

\section{Statistical analysis}

All data were analyzed with Stata 12.1 (StataCorp, College Station, TX). All 2-tailed values of $p \leq 0.05$ were considered statistically significant. 
Table 1 Details of included cohorts, baseline with first-ever strokes, and long-term functional outcome and participation after stroke

\begin{tabular}{|c|c|c|c|c|c|c|c|c|c|}
\hline \multirow[b]{2}{*}{ Study } & \multirow[b]{2}{*}{ ID } & \multirow[b]{2}{*}{$\begin{array}{l}\text { Study } \\
\text { year }\end{array}$} & \multirow[b]{2}{*}{$\begin{array}{l}\text { Baseline, } \\
\text { n }\end{array}$} & \multicolumn{3}{|l|}{ 1-y Outcome } & \multicolumn{3}{|l|}{ 5-y Outcome } \\
\hline & & & & Survivor, n & $\begin{array}{l}\text { Assessed, } \\
\text { n }\end{array}$ & Instrument & $\begin{array}{l}\text { Survivors, } \\
\mathrm{n}\end{array}$ & Assessed, $n$ & Instrument \\
\hline Oxford, UK & A & $2002-2013$ & 1,374 & 988 & 910 & $\mathrm{mRS}$ & $403^{a}$ & 385 & $\mathrm{mRS}$ \\
\hline Joinville, Brazil & $\mathrm{B}$ & 2009-2014 & 2,448 & 1,869 & 1,708 & $\mathrm{mRS}$ & $598^{a}$ & 423 & $\mathrm{mRS}$ \\
\hline \multirow[t]{2}{*}{$\begin{array}{l}\text { Melbourne, } \\
\text { Australia }\end{array}$} & $\mathrm{C}$ & 1996-1999 & $1,248^{b}$ & 806 & 494 & $\mathrm{BI}$ & 553 & 460 & $\mathrm{BI}$ \\
\hline & & & & & & & & 351 & LHS \\
\hline Arcadia, Greece & $\mathrm{D}$ & 1993-1995 & 555 & 342 & 328 & $\mathrm{mRS}$ & - & - & - \\
\hline Perth, Australia & $\mathrm{E}$ & $2000-2001$ & 183 & 120 & 36 & $\mathrm{mRS} / \mathrm{BI}$ & - & - & - \\
\hline Orebro, Sweden & $\mathrm{F}$ & $1999-2000$ & $377^{b}$ & 253 & 253 & $\mathrm{mRS} / \mathrm{BI}$ & - & - & - \\
\hline $\begin{array}{l}\text { Martinique, } \\
\text { French West } \\
\text { Indies }\end{array}$ & $\mathrm{H}$ & 1998-1999 & 580 & 391 & 391 & $\mathrm{mRS}$ & 265 & 265 & $\mathrm{mRS}$ \\
\hline Porto, Portugal & 1 & $1998-2000$ & 688 & 484 & 484 & $\mathrm{mRS}$ & $281(7 y)^{c}$ & 259 & $\mathrm{mRS}$ \\
\hline \multirow{2}{*}{$\begin{array}{l}\text { Auckland, New } \\
\text { Zealand }\end{array}$} & $\mathrm{K}$ & $2002-2003$ & 1,423 & 993 & - & - & 881 & 303 & $\mathrm{mRS} / \mathrm{BI}$ \\
\hline & & & & & & & & 266 & LHS \\
\hline Matão, Brazil & M & 2003-2004 & 81 & 56 & 54 & $\mathrm{BI}$ & - & - & - \\
\hline Tartu, Estonia & $\mathrm{N}$ & $2002-2003$ & $433^{b}$ & 245 & 194 & $\mathrm{mRS} / \mathrm{BI}$ & $161(4 y)^{c}$ & 131 & $\mathrm{mRS}$ \\
\hline Total cases & & & 9,390 & $\begin{array}{l}5,554 / 7,640 \\
\text { baseline }\end{array}$ & $\begin{array}{l}\mathrm{mRS} / \mathrm{BI} \\
4,852\end{array}$ & $\begin{array}{l}\text { mRS 3,393; } \\
\text { BI 2,531 }\end{array}$ & $\begin{array}{l}3,142 / 5,799 \\
\text { baseline }\end{array}$ & $\begin{array}{l}\mathrm{mRS} / \mathrm{BI} \\
2,226 ; \mathrm{LHS} \\
617\end{array}$ & $\begin{array}{l}\text { mRS 1,766; BI } \\
\text { 591; LHS } 617\end{array}$ \\
\hline
\end{tabular}

Abbreviations: $\mathrm{BI}=$ Barthel Index; ID = identification; LHS = London Handicap Scale; $\mathrm{mRS}$ = modified Rankin Scale.

a Follow-up data to 5 years were available only among cases with year of stroke from 2002 to 2008 for Oxford ( $n=760$ at baseline) or with year of stroke from 2009 to 2011 for Joinville ( $n=1,020$ at baseline).

${ }^{b}$ Not including cases with subarachnoid hemorrhagic stroke at baseline.

' Follow-up data on functional outcome were available only at 4 years (for Tartu) or 7 years (for Porto).

A 2-stage analysis method ${ }^{15}$ was used to perform random-effects meta-analysis because many covariates were inconsistently measured between studies from different populations. For the first stage, study-specific estimates of unadjusted and adjusted female:male relative risk (RR) of poor functional outcome at 1 year (10 studies) and 5 years ( 7 studies) after stroke were made with multivariable log-binomial regression. Functional outcomes available at 4 years (Tartu) or 7 years (Porto) were included in 5-year analyses. For analyses of participation restriction, study-specific multivariable linear regression with transformation (appendix e-3, links.lww.com/WNL/A488) was used to compare the mean difference (MD) of LHS total scores (0-100) for women and men (2 studies, Melbourne and Auckland).

Within each study, we assessed the confounding role ${ }^{16}$ of covariates in the association between sex and each outcome. Adjustment was done for each variable separately and then for all confounders in multivariable analyses but with age, stroke severity, and prestroke function (where available) forced into a final fully adjusted model (appendix e-3, links.lww.com/
WNL/A488). These confounders were further assessed for interaction with sex within each study.

For the second stage of the analysis, unadjusted and adjusted study-specific estimates were pooled in separate metaanalyses, so that the pooled values could be compared to determine the effect of adjustment. Heterogeneity was evaluated with $I^{2}$ statistics. Meta-regression was used to account for sources of heterogeneity among study-level characteristics ( $n=14$ variables, appendix e-3, links.lww.com/WNL/A488).

Three covariates were measured consistently in all studies: year of stroke occurrence, age, and stroke type. To further test the robustness of our findings, we used a single-stage metaanalysis pooling all IPD datasets ${ }^{17}$ to examine whether these factors modified the sex effect on poor functional outcome.

\section{Sensitivity analyses}

In studies with $>20 \%$ of data missing on long-term functional outcomes, participation restriction, or covariates, multiple imputation $^{18}$ and further sensitivity analyses were performed and 
compared with results from complete-case analyses (appendix e-3, links.lww.com/WNL/A488). We performed sensitivity analyses by conducting ordinal modeling of the $\mathrm{mRS}$ score, using alternative cut points to define poor outcome with the BI, analyzing subdomain scores of LHS, and (in a subset of studies) including clinical management as covariates (appendix e-3).

\section{Data availability}

For purposes of replicating procedures and results, qualified investigators can request access to patient-level data after ethics clearance and approval by all authors.

\section{Results}

Functional outcomes were assessed among 4,852 (87.3\%) of 5,554 survivors at 1 year and 2,226 (70.8\%) of 3,142 survivors at 5 years after stroke (table 1). Participation restriction was assessed among $617(43.0 \%)$ of 1,434 survivors at 5 years in 2 of the studies (table 1).

\section{Sex differences in demographics and risk factors}

In analyses of baseline factors, among those assessed at 1 year after stroke (table e-3, links.lww.com/WNL/A490), women were older (statistically significant difference in 8 of 10 studies), more often living without a spouse ( 2 of 3 studies), more often living in institutions ( 2 of 3 studies), and more often dependent before stroke than men (4 of 6 studies). Men were more frequently ever-smokers ( 9 of 9 studies) or alcohol consumers ( 7 of 8 studies) than women. Female survivors at 1 year had more severe strokes than male survivors, with a higher mean score of stroke severity in each study

Figure 1 RR of poor functional outcome at 1 year after stroke for women vs men in (A) unadjusted and (B) adjusted analyses among 10 studies combined using random-effects meta-analysis

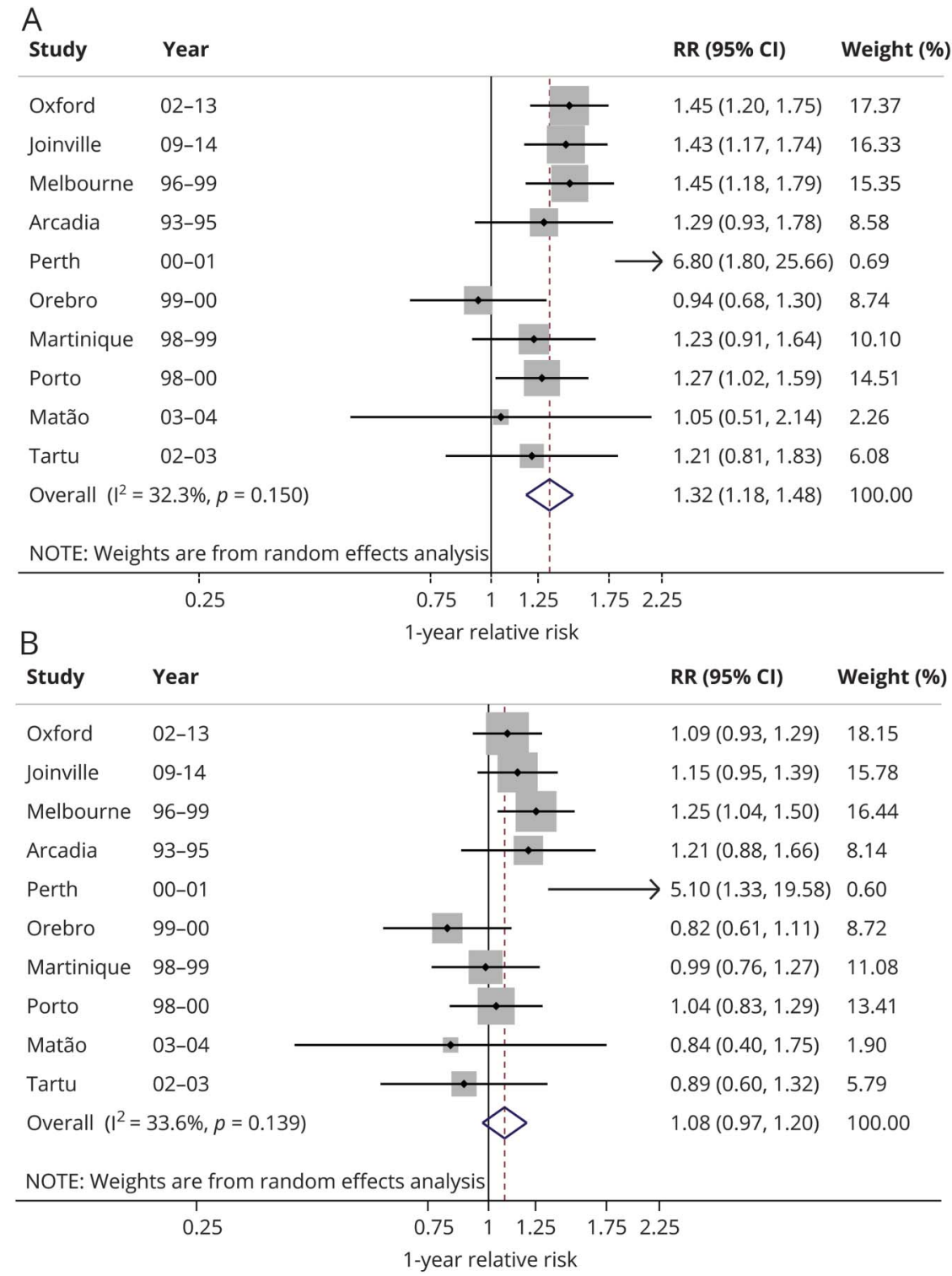

Poor outcome was defined as a Barthel Index score <20 (Melbourne and Matão) and modified Rankin Scale score $>2$ (remaining studies). $\mathrm{Cl}=$ confidence interval; $\mathrm{RR}=$ relative risk. 
(significant difference in only 3 of 10 studies). Female survivors at 5 years (table e- 4 ) were older at stroke onset than male survivors (significant difference 3 of 7 studies), and a greater proportion had prestroke dependency (4 of 5 studies).

\section{Sex differences in functional outcomes}

Analysis of 1-year functional outcome among 10 studies included 4,657 cases after $4 \%$ of available cases were excluded because of missing data on confounders. In unadjusted analyses, women had a $32 \%$ greater risk of poor functional outcome than men (figure 1, top). There was no between-study heterogeneity $\left(I^{2}=32.3, p=0.150\right)$. The pooled adjusted RR was 1.08 (95\% confidence interval $[\mathrm{CI}] 0.97-1.20, I^{2}=33.6, p=0.139$; figure 1 , bottom). The factors identified as important confounders of the sex differences in functional outcomes included age at baseline ( 9 of 10 studies), stroke severity (8 of 10 studies), and prestroke dependency (5 of 6 studies; table 2). Only in 2 of 10 studies (Melbourne and Perth) did the poorer functional outcomes for women remain statistically significant after adjustment for these 3 factors (figure 1). There was no evidence that socioeconomic status, cardiovascular risk factors, medical comorbidities, stroke recurrence, and poststroke depression were confounders of the differences (table e-5, links.lww.com/WNL/A490). Adjustment for age alone explained $43 \%$ of the sex difference (pooled $\mathrm{RR}_{\text {age- }}$ adjusted 1.17, 95\% CI 1.06-1.30). The pooled unadjusted female: male RR was also reduced with separate adjustment for stroke severity (20\%) and prestroke dependency (45\%; table e-6A).
Only in the Oxford and Melbourne study, in which the risk of worse functional outcome for women was greater among persons who were independent before stroke (table e-6B), was statistical interaction present. Use of meta-regression did not reveal any sources of heterogeneity (table e-7A). In further analyses of the IPD data, none of the 3 participant-level characteristics of age, stroke type, and year of stroke occurrence were significant sources of between-study variation (table e-7B).

Sensitivity analyses using an alternative cut point for the BI (table e-8, links.lww.com/WNL/A490), ordinal regression model of mRS score (figure e-2, links.lww.com/WNL/A489), and imputation of missing data in 3 studies with substantial missing data (tables e- 9 and e-10, A and B) demonstrated that our primary findings were robust (table e-11).

Analyses were repeated for 5-year functional outcomes in 7 studies ( $\mathrm{n}=2,084,94 \%$ of available cases). Women had a $31 \%$ greater risk of poor functional outcome at 5 years (figure 2, top) than men. Adjusted results showed no sex difference (RR 1.05, 95\% CI 0.94-1.18; figure 2, bottom) after accounting for age, stroke severity, and prestroke dependency (table 2). Full details of the adjusted analyses (table e-6, A and B, links.lww.com/WNL/A490) and sensitivity analyses are provided in appendix e-4, links.lww. com/WNL/A488, tables e-7B through e-13, and figure e-3, links.lww.com/WNL/A489.

Table 2 Confounding factors contributing to sex difference in long-term functional outcome after stroke based on the fully adjusted model within studies

\begin{tabular}{|c|c|c|c|c|}
\hline \multirow[b]{2}{*}{ Study } & \multicolumn{2}{|l|}{$1-y$} & \multicolumn{2}{|l|}{$5-y$} \\
\hline & No. & Confounders $^{a}$ & $\mathbf{N}$ & Confounders $^{a}$ \\
\hline Oxford & 895 & Age, log NIHSS, ${ }^{b}$ prestroke mRS & 378 & Age, NIHSS, ${ }^{c}$ prestroke mRS, marital status \\
\hline Joinville & 1,708 & Age, NIHSS & 423 & $\mathrm{Age}_{,}^{\mathrm{c}} \mathrm{NIHSS}^{\mathrm{c}}$ \\
\hline Melbourne & 415 & Age, log NIHSS, ${ }^{b}$ prestroke $\mathrm{BI}^{\mathrm{c}}$ & 368 & Age, NIHSS, dementia, prestroke $\mathrm{BI}^{\mathrm{c}}$ \\
\hline Arcadia & 327 & Age, GCS & - & - \\
\hline Perth & 36 & Age, NIHSS, ${ }^{c}$ prestroke mRS & - & - \\
\hline Orebro & 253 & Age, NIHSS, prestroke Barthel & - & - \\
\hline Martinique & 328 & Age, $\mathrm{Bl}$ at onset & 224 & Age, $\mathrm{Bl}$ at onset \\
\hline Porto & 477 & Age, LOC, ${ }^{\mathrm{C}}$ prestroke $\mathrm{mRS}$ & 258 & Age (2-term), ${ }^{\mathrm{b}} \mathrm{LOC}^{\mathrm{c}}{ }^{\mathrm{c}}$ prestroke $\mathrm{mRS}^{2}{ }^{\mathrm{b}}$ \\
\hline Auckland & - & - & 302 & $\mathrm{Age}^{3}, \mathrm{GCS}^{\mathrm{c}}$ prestroke dependency ${ }^{\mathrm{d}}$ \\
\hline Matão & 54 & Age, NIHSS & - & - \\
\hline Tartu & 164 & Age, ${ }^{c}$ NIHSS, prestroke mRS & 131 & Inverse age ${ }^{2},{ }^{b}$ NIHSS, ${ }^{c}$ prestroke $\mathrm{mRS}^{\mathrm{c}}$ \\
\hline Total cases & 4,657 & & 2,084 & \\
\hline
\end{tabular}

Abbreviations: BI = Barthel Index; GCS = Glasgow Coma Scale; LOC = loss of consciousness; mRS = modified Rankin Scale; NIHSS = NIH Stroke Scale.

a Criteria of being a confounder included the following: (1) the covariate was missing in $<20 \%$ of cases; (2) the covariate was associated with outcome, $p<0.1$; (3) the covariate was associated with the exposure, sex, $p<0.1$; and (4) the inclusion of the covariate in a model with only sex changed the magnitude of the sex coefficient by $\geq 10 \%$.

b Transformations were based on the powers (e.g., second power, 2-power terms, logarithm of covariates) suggested by fractional polynomials because this combination was found to produce the best-fitting multivariable model.

c Not meeting criteria of being a confounder but being forced into the fully adjusted multivariable model.

${ }^{d}$ Assessed by whether the patient was living independently before stroke. 


\section{Contribution of stroke management to poor functional outcomes based on sex}

In a subset of hospitalized patients, there was little evidence of sex differences in the acute treatment and management of stroke among survivors at 1 and 5 years (tables e-14 and e-15, links.lww.com/WNL/A490). None of the factors confounded or modified the association between sex and functional outcomes (figures e-4 and e-5, links.lww.com/WNL/A489).

\section{Sex differences in participation restriction}

Five years after stroke, data on participation restriction were collected from 351 of 553 (63\%) survivors in Melbourne and 266 of 881 (30\%) survivors in Auckland (table 1). Men had less participation restriction than women (figure e-6, links. lww.com/WNL/A489).

The pooled unadjusted MD in overall LHS score between women and men was -5.55 (95\% CI -8.47 to -2.63$)$. After adjustment for confounders-age, prestroke dependency, prestroke dementia (Melbourne), and stroke severity (Melbourne; table 3) - in study-specific models, the magnitude of the sex difference was attenuated by $55 \%\left(\mathrm{MD}_{\mathrm{ad}}-\right.$ justed $-2.48,95 \% \mathrm{CI}-4.99$ to 0.03 ). There were no significant interactions between sex and these factors in the association with participation restriction. Covariates that did not confound the association are reported in table e-16, links.lww. com/WNL/A490. Further sensitivity analyses suggests that our results were robust (table e-17). In subdimensions of participation (figure e-7, links.lww.com/WNL/A489), women had greater restriction than men in nearly all of the domains (table e-18).

\section{Discussion}

Women had worse functional outcomes and greater participation restriction than men in the long term after stroke;

Figure 2 RR of poor functional outcome at 5 years after stroke for women vs men in (A) unadjusted and (B) adjusted analyses among 7 studies combined using random-effects meta-analysis

A

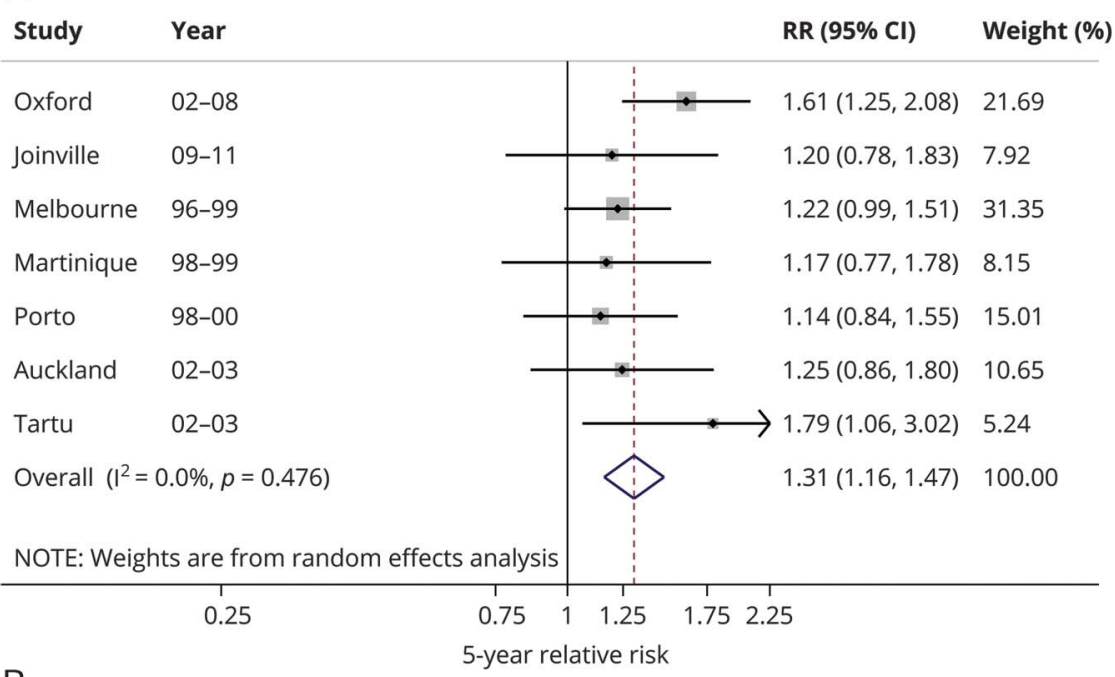

B

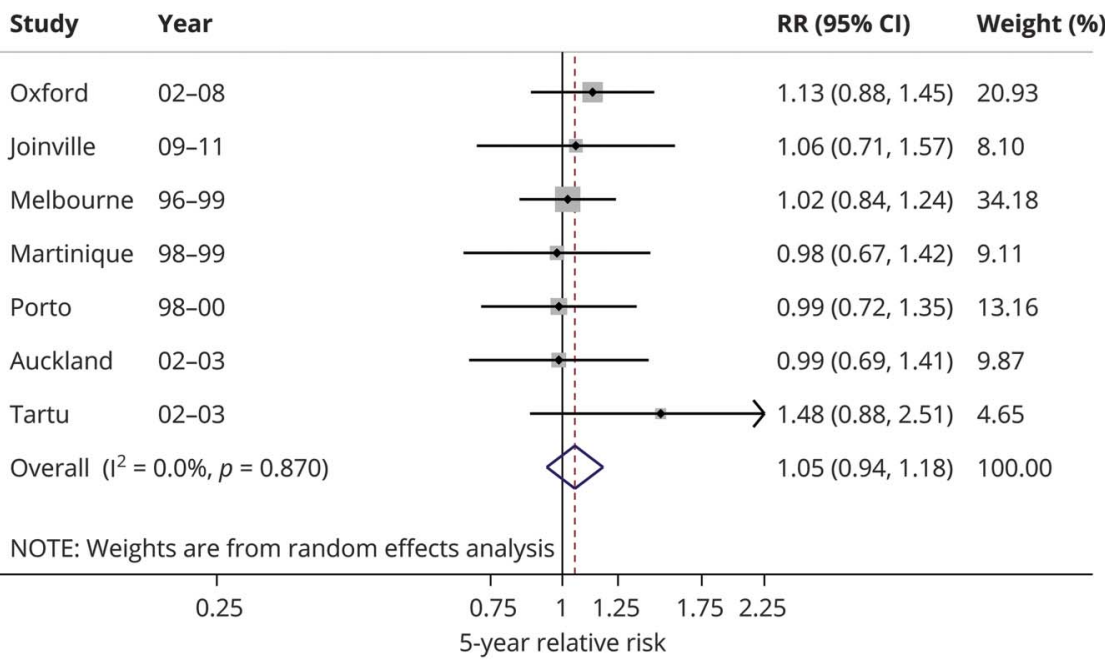

Poor outcome was defined as a Barthel Index score $<20$ (Melbourne) or modified Rankin Scale score $>2$ (remaining studies). $\mathrm{Cl}=$ confidence interval; $\mathrm{RR}=$ relative risk 
Table 3 Sex difference in participation restriction at 5 years among 2 studies (Melbourne and Auckland) with the LHS

\begin{tabular}{|c|c|c|c|}
\hline & \multicolumn{3}{|c|}{ Melbourne $(n=351)$} \\
\hline & MD & $95 \% \mathrm{Cl}$ & $\Delta, \%^{\mathrm{a}}$ \\
\hline Unadjusted & -6.89 & -10.71 to -3.07 & \\
\hline \multicolumn{4}{|l|}{ Adjusted for } \\
\hline $\operatorname{Age}^{b}$ & -5.33 & -8.78 to -1.87 & 23 \\
\hline Institutional residence & -6.06 & -9.82 to -2.31 & 12 \\
\hline Prestroke $\mathbf{B I}^{\mathbf{b}}$ & -5.88 & -9.69 to -2.07 & 15 \\
\hline Dementiab $^{b}$ & -5.79 & -9.56 to -2.03 & 16 \\
\hline NIHSS $^{b}$ & -5.61 & -9.27 to -1.95 & 19 \\
\hline \multirow[t]{3}{*}{ Full model $^{\mathrm{d}}$} & -2.74 & -5.95 to 0.47 & 60 \\
\hline & \multicolumn{3}{|c|}{ Auckland ( $n=265)$} \\
\hline & MD & $95 \% \mathrm{Cl}$ & $\Delta, \%^{\mathrm{a}}$ \\
\hline Unadjusted & -3.89 & -8.16 to 0.37 & \\
\hline \multicolumn{4}{|l|}{ Adjusted for } \\
\hline $\operatorname{Age}^{\mathrm{b}}$ & -2.81 & -7.00 to 1.38 & 28 \\
\hline Prestroke dependency & -3.12 & -7.25 to 1.01 & 20 \\
\hline $\mathbf{G C S}^{\mathrm{b}, \mathrm{c}}$ & -3.86 & -8.12 to 0.41 & 1 \\
\hline LOC & -3.62 & -7.80 to 0.57 & 7 \\
\hline Full model $^{d}$ & -2.05 & -6.12 to 2.01 & 47 \\
\hline \multicolumn{4}{|c|}{$\begin{array}{l}\text { Abbreviations: } \mathrm{BI}=\text { Barthel Index; } \mathrm{Cl}=\text { confidence interval; GCS = Glasgow Coma Scale; LOC = loss of consciousness; LHS = London Handicap Sca } \\
\text { difference; NIHSS = NIH Stroke Scale. } \\
\text { a Percent change of coefficient of sex difference between unadjusted and adjusted models was calculated by the formula (unadjusted } \beta \text { - a } \\
\text { adjusted } \beta \times 100 \text {. } \\
\text { b Denotes covariates that remained in the final model. } \\
{ }^{c} \text { Not meeting criteria of being a confounder but remaining in the fully adjusted multivariable model. } \\
{ }^{d} \text { Full models were adjusted for age, prestroke dependency, and severity at baseline; age required quadratic term in the final model (age }{ }^{3} \text { ). }\end{array}$} \\
\hline
\end{tabular}

however, these differences were greatly diminished after adjustment for major confounding factors.

Age was one of the most important factors contributing to the sex differences in the outcomes examined ( $43 \%$ to functional outcomes, $25 \%$ to participation restriction). The elderly often present with more severe strokes and comorbidities, ${ }^{19}$ which are associated with poorer recovery after stroke. Older people are also less often admitted to hospital and may not receive a full diagnostic workup or care in a stroke unit, ${ }^{20}$ thereby contributing to their worse functional outcomes. One interpretation of older age at stroke onset in women is the success of preventive efforts because they live stroke free for longer, but as a consequence, they are then frailer and have less capacity to recover after stroke compared to men.

More severe strokes in women often contributed to the sex difference in functional outcome and participation restriction. In each study, the mean stroke severity score was consistently higher in women but only significantly different in 3 studies.
Factors known to be modifiable contributors to stroke severity include hypertension, ${ }^{21}$ hyperlipidemia, ${ }^{21}$ and atrial fibrillation, ${ }^{22}$ but their relative importance to severity in women compared to men is unknown.

Worse prestroke function in women was another important confounder of the sex differences in the outcomes. Having existing functional limitations may affect discharge destination, particularly the choice of rehabilitation setting. ${ }^{23}$ This can greatly affect subsequent rehabilitation outcomes, especially functional recovery, in women after stroke. ${ }^{24}$ The presence of prestroke functional limitation may also contribute to participation restriction after stroke through reduced autonomy and social interactions. ${ }^{25}$

The sex difference in outcomes after stroke disappeared after accounting for age, stroke severity, and prestroke function. However, in 2 of 10 studies, the poorer functional outcome in women was not fully explained by these 3 factors. There might be other biological, social, or psychological differences between men and women accounting for differences in 
outcomes. One possibility is that women's greater musculoskeletal pain and fear of falling ${ }^{26}$ could be barriers to engaging in effective rehabilitation, which could affect their functional recovery and participation restriction after stroke. Another possible explanation is sex differences in perceived physical ability. ${ }^{27}$ For example, women generally report greater fear of injury and risk taking compared to men. ${ }^{28}$ They may therefore perform fewer activities such as stair climbing even though they are physically capable. This may translate to worse scores on measures of functional ability for women. Because of women's greater social isolation, more social supports may be needed to reduce sex differences in long-term outcomes of stroke. $^{29}$

On the basis of these findings, we can suggest some strategies to address the sex differences in outcomes after stroke. Given the overwhelming role of age on outcomes, the development of evidence-based recommendations applicable to older patients for healthy aging, stroke prevention, and clinical management of cardiovascular diseases is of utmost importance. ${ }^{30}$ Although poorer outcomes after stroke in the elderly are to some degree inevitable because of functional deterioration and multimorbidity, we may be able to moderate the impact of stroke by providing evidence for acute stroke care in older people with frailty because such people are often excluded from trials. ${ }^{30}$

Better rehabilitation of those with prestroke functional limitations may assist women with stroke to recover their function and increase participation. Some allied health interventions such as strength and aerobic exercise and support services appear to increase participation, ${ }^{31}$ but these programs are not widely available. Consequently, there is a need to implement effective community-based poststroke rehabilitation, ${ }^{25}$ especially targeting those who have less capacity to recover. More generally, efforts to help older women maintain their physical function in the general population should be a priority.

Further examination of the causes of the sex difference in stroke severity may identify novel targets to lessen the severity and improve outcomes in women. These differences may be biological or clinical and therefore amenable to intervention. However, they could also be an artifact of measurement, with others reporting that severity assessments are affected by frailty and comorbidities, which are more common in women. ${ }^{32}$ In general, it may be necessary to re-evaluate all stroke assessment scales in terms of their suitability across different patient groups, including women, to ensure that they are robust measures of the patient experience. ${ }^{33}$ Until we better understand the sex difference in stroke severity, we should optimize control of the risk factors that are associated with severity and poor outcome of stroke, especially in women. $^{34}$

Participation restriction is an important patient-centered outcome after stroke, but data are scarce. Current participation instruments (e.g., LHS) were designed to evaluate health care interventions in population rather than individuals, ${ }^{35}$ and the assessments may reflect what people do, not what they can do. ${ }^{36}$ We therefore examined the sex differences in some but not all dimensions of participation, e.g., communication or household tasks. ${ }^{37}$ New instruments to improve the measurement of patient-centered outcomes may address these problems. ${ }^{5}$

This study has several limitations. Three eligible stroke incidence studies that did not participate in INSTRUCT (appendix e-1, links.lww.com/WNL/A488, and table e-1, links.lww.com/WNL/A490) had no sex-specific reports on relevant outcomes to compare our findings. The variation in definitions and measurement of covariates may lead to some bias in the adjusted estimates. Furthermore, there were few data on stroke management and poststroke depression. However, in the studies that included measures of quality of care and depression and in those by other investigators, ${ }^{38}$ these factors did not appear to confound the association between sex and functional outcomes. Age, prestroke dependency, and stroke severity were also strongly predictive of mortality after stroke. However, this is unlikely to have influenced our findings because women were also more likely to die after stroke in these data ${ }^{9}$ and the current analyses were limited to survivors. Prestroke dependency contributed to the sex difference in functional outcome, but differing measures were used to assess this ( $\mathrm{mRS}, \mathrm{BI}$, institutional residence). The effect of adjustment was greater in the studies with detailed measures of prestroke function ( $\mathrm{mRS}, \mathrm{BI})$, suggesting that our adjusted estimates may have residual confounding. The missing data on long-term outcome in some studies (i.e., Melbourne, Perth, Auckland) are potentially a significant methodologic limitation. However, the results of sensitivity analyses using multiple imputation methods (table e-11) suggest that the missing data did not markedly influence our results, but we cannot preclude the possibility of bias.

Several strengths need to be acknowledged. This is an innovative collaborative study in which individual long-term outcome data were obtained from high-quality populationbased studies from various countries, making our results generalizable and adequately powered. We examined the role of confounding factors on the sex difference in outcomes using purposeful model building ${ }^{16}$ rather than step-wise methods, providing more reliable unadjusted and adjusted pooled estimates compared to the original studies. Sex differences in long-term functional outcomes and participation restriction after stroke were due largely to women's advanced age, more severe stroke, and prestroke functional limitation but not to stroke care. Population-based interventions are needed to decrease sex disparities in these outcomes. Interventions may include reducing the risk factors of stroke particularly in women and the elderly, as well as better measurement and management of functional limitations in women as they age. 


\section{Author contributions}

Dr. Phan: study concept and design, acquisition, analysis and interpretation of data, literature review, and drafting of the manuscript. Dr. Blizzard, Dr. Reeves, Dr. Thrift, Dr. Cadilhac, Dr. Sturm, Dr. Heeley, and Mr. Otahal: study concept and design, interpretation of data, and critical revision of manuscript for intellectual content. Dr. Vemmos, Dr. Anderson, Dr. Parmar, Dr. Krishnamurthi, Dr. Barker-Collo, Dr. Feigin, Dr. Bejot, Dr. Cabral, Dr. Carolei, Dr. Sacco, Dr. Chausson, Dr. Olindo, Dr. Rothwell, Dr. Silva, Dr. Correia, Dr. Magalhães, Dr. Appelros, Dr. Kõrv, Dr. Vibo, and Dr. Minelli: study concept and design, interpretation of data, and revision of manuscript for intellectual content. Dr. Gall: study concept and design, supervision of the study, acquisition, interpretation of data, and critical revision of manuscript for intellectual content.

\section{Study funding}

Chief investigators for each of the studies provided their data at no cost. H.T.P. is supported by a Merle Weaver Postgraduate Scholarship (University of Tasmania). S.L.G. is supported by a National Heart Foundation of Australia Future Leader Fellowship (FLF 100446). M.J.R. was supported by a Menzies Institute Visiting scholars program (Tasmania, Australia). The following authors received research fellowship funding from the National Health and Medical Research Council (NHMRC): A.G.T. (1042600), D.A.C. (cofunded Heart Foundation: 1063761), and C.A. (1081356). The NHMRC also provided support for the study conducted in Melbourne (154600, 307900), as did VicHealth and the Stroke Foundation (Australia). The Health Research Council of New Zealand funded the research conducted in Auckland. The Brazilian National Council for Scientific and Technological Development (CNPq) funded the research conducted in Joinville (grant 402396/2013-8). The Oxford Vascular Study is funded by the Wellcome Trust, Stroke Association, and National Institute of Health Research Biomedical Research Centre, Oxford.

\section{Disclosure}

The authors report no disclosures relevant to the manuscript. Go to Neurology.org/N for full disclosures.

Received September 20, 2017. Accepted in final form February 23, 2018.

\section{References}

1. Lundberg GP, Volgman AS. Burden of stroke in women. Trends Cardiovasc Med 2016;26:81-88.

2. Persky RW, Turtzo LC, McCullough LD. Stroke in women: disparities and outcomes. Curr Cardiol Rep 2010;12:6-13.

3. Petrea RE, Beiser AS, Seshadri S, Kelly-Hayes M, Kase CS, Wolf PA. Gender differences in stroke incidence and poststroke disability in the Framingham Heart Study. Stroke 2009;40:1032-1037.

4. Gall SL, Tran PL, Martin K, Blizzard L, Srikanth V. Sex differences in long-term outcomes after stroke: functional outcomes, handicap, and quality of life. Stroke 2012; 43:1982-1987.

5. Salinas J, Sprinkhuizen SM, Ackerson T, et al. An international standard set of patientcentered outcome measures after stroke. Stroke 2016;47:180-186.

6. Sturm JW, Donnan GA, Dewey HM, et al. Quality of life after stroke: the North East Melbourne Stroke Incidence Study (NEMESIS). Stroke 2004;35:2340-2345.

7. Reeves MJ, Lisabeth LD. The confounding issue of sex and stroke. Neurology 2010; 74:947-948
8. Appelros P, Hogeras N, Terent A. Case ascertainment in stroke studies: the risk of selection bias. Acta Neurol Scand 2003;107:145-149.

9. Phan HT, Blizzard CL, Reeves MJ, et al. Sex differences in long-term mortality after stroke in the INSTRUCT (INternational STRoke oUtComes sTudy). Circ Cardiovasc Qual Outcomes 2017;10:e003436.

10. Phan H, Blizzard L, Thrift A, et al. Sex Difference in Long-term Outcomes of Stroke in the INternational STroke OUtComes STudy (INSTRUCT): A Meta-analysis of Individual Patient Data: PROSPERO 2016: CRD42016036723. York, UK: Centre for Reviews and Dissemination, University of York; 2016. Available at: crd.york.ac.uk/ PROSPERO/display_record.asp?ID=CRD42016036723. Accessed September 12, 2016.

11. Stewart LA, Clarke M, Rovers M, et al. Preferred reporting items for systematic review and meta-analyses of individual participant data: the PRISMA-IPD statement. JAMA 2015;313:1657-1665.

12. Sulter G, Steen C, Keyser JD. Use of the Barthel Index and modified Rankin Scale in acute stroke trials. Stroke 1999;30:1538-1541.

13. Sturm JW, Dewey HM, Donnan GA, Macdonell RAL, McNeil JJ, Thrift AG. Handicap after stroke: how does it relate to disability, perception of recovery, and stroke subtype? The North East Melbourne Stroke Incidence Study (NEMESIS). Stroke 2002; 33:762-768.

14. Harwood RH, Ebrahim S. The London Handicap Scale. J Neurol Neurosurg Psychiatry 2000;69:406.

15. Stukel TA, Demidenko E, Dykes J, Karagas MR. Two-stage methods for the analysis of pooled data. Stat Med 2001;20:2115-2130.

16. Greenland S. Modeling and variable selection in epidemiologic analysis. Am J Public Health 1989;79:340-349.

17. Stewart GB, Altman DG, Askie LM, Duley L, Simmonds MC, Stewart LA. Statistical analysis of individual participant data meta-analyses: a comparison of methods and recommendations for practice. PLoS One 2012;7:e46042.

18. Seaman SR, White IR, Copas AJ, Li L. Combining multiple imputation and inverseprobability weighting. Biometrics 2012;68:129-137.

19. Gur AY, Tanne D, Bornstein NM, et al. Stroke in the very elderly: characteristics and outcome in patients aged $>/=85$ years with a first-ever ischemic stroke. Neuroepidemiology 2012;39:57-62.

20. Russo T, Felzani G, Marini C. Stroke in the very old: a systematic review of studies on incidence, outcome, and resource use. J Aging Res 2011;2011:108785.

21. Faraji F, Ghasami K, Talaie-Zanjani A, Mohammadbeigi A. Prognostic factors in acute stroke, regarding to stroke severity by Canadian Neurological Stroke Scale: a hospitalbased study. Asian J Neurosurg 2013;8:78-82.

22. Kakar P, Boos CJ, Lip GYH. Management of atrial fibrillation. Vasc Health Risk Manag 2007;3:109-116.

23. Fox J, Garber P, Hoffman M, et al. Morphological characteristics of skeletal muscles in relation to gender. Aging Clin Exp Res 2003;15:264-269.

24. Paolucci S, Bragoni M, Coiro P, et al. Is sex a prognostic factor in stroke rehabilitation? A matched comparison. Stroke 2006;37:2989-2994.

25. Winstein CJ, Stein J, Arena R, et al. Guidelines for adult stroke rehabilitation and recovery: a guideline for healthcare professionals from the American Heart Association/American Stroke Association. Stroke 2016;47:e98-e169.

26. Aberg AC. Gender comparisons of function-related dependence, pain and insecurity in geriatric rehabilitation. J Rehabil Med 2005;37:378-384.

27. Roding J, Glader EL, Malm J, Eriksson M, Lindstrom B. Perceived impaired physical and cognitive functions after stroke in men and women between 18 and 55 years of age: a national survey. Disabil Rehabil 2009;31:1092-1099.

28. Harris CR, Jenkins M, Glaser D. Gender differences in risk assessment: why do women take fewer risks than men? Judgment Decis Making 2006;1:48.

29. Reeves MJ, Bushnell CD, Howard G, et al. Sex differences in stroke: epidemiology, clinical presentation, medical care, and outcomes. Lancet Neurol 2008;7:915-926.

30. Rich MW, Chyun DA, Skolnick AH, et al. Knowledge gaps in cardiovascular care of the older adult population: a scientific statement from the American Heart Association, American College of Cardiology, and American Geriatrics Society. Circulation 2016;133:2103-2122.

31. Obembe AO, Eng JJ. Rehabilitation interventions for improving social participation after stroke: a systematic review and meta-analysis. Neurorehabil Neural Repair 2016; 30:384-392.

32. Abdul-Rahim AH, Fulton RL, Sucharew H, et al. National Institutes of Health Stroke Scale item profiles as predictor of patient outcome: external validation on independent trial data. Stroke 2015;46:395-400.

33. Kapoor A, Lanctôt KL, Bayley M, et al. "Good outcome" isn't good enough: cognitive impairment, depressive symptoms, and social restrictions in physically recovered stroke patients. Stroke 2017;48:1688-1690.

34. Bushnell C, McCullough LD, Awad IA, et al. Guidelines for the prevention of stroke in women: a statement for healthcare professionals from the American Heart Association/American Stroke Association. Stroke 2014;45:1545-1588.

35. Harwood RH, Rogers A, Dickinson E, Ebrahim S. Measuring handicap: the London Handicap Scale, a new outcome measure for chronic disease. Qual Health Care 1994; 3:11-16.

36. Hammel J, Magasi S, Heinemann A, Whiteneck G, Bogner J, Rodriguez E. What does participation mean? An insider perspective from people with disabilities. Disabil Rehabil 2008;30:1445-1460.

37. Tse T, Douglas J, Lentin P, Carey L. Measuring participation after stroke: a review of frequently used tools. Arch Phys Med Rehabil 2013;94:177-192.

38. Kim JS, Lee KB, Roh H, Ahn MY, Hwang HW. Gender differences in the functional recovery after acute stroke. J Clin Neurol 2010;6:183-188. 


\section{Factors contributing to sex differences in functional outcomes and participation after stroke}

Hoang T. Phan, MD, Christopher L. Blizzard, PhD, Mathew J. Reeves, PhD, et al. Cite as: Neurology ${ }^{\circledR}$ 2018;90:e1945-e1953. doi:10.1212/WNL.0000000000005602
Correspondence

Dr. Gall

Seana.Gall@utas.edu.au

\section{Study question}

What factors contribute to between-sex differences in functional outcomes in the long term after stroke?

\section{Summary answer}

Age, stroke severity, and prestroke dependency account for women's functional outcomes in the long-term after stroke being worse than those of men.

\section{What is known and what this paper adds}

It is established that long-term functional outcomes are worse in women than in men, but relatively few studies have investigated the reasons. This study uses pooled data from high-quality population-based studies on long-term functional outcomes after stroke to clarify the factors underlying between-sex differences.

\section{Participants and setting}

This study examined data from 11 previous studies that together included 9,390 stroke patients at baseline. These studies were conducted in Australasia, Europe, South America, and the Caribbean. The earliest starting year among the studies was 1993, and the latest concluding year was 2014.

\section{Design, size, and duration}

Among the previous studies, 9 collected follow-up data from participants through in-person interviews, and 2 used mail or telephone interviews. Follow-up data at the 1-year poststroke time point were available for 4,852 participants from 10 studies, and 5-year follow-up data were available for 2,226 participants from 7 studies. This study used multivariable log-binomial regression to estimate the female:male relative risk (RR) of poor functional outcomes and then examined how the RR was affected after adjustment for various factors previously identified as possibly contributing to between-sex outcome differences. These factors included sociodemographic characteristics, prestroke health, stroke-related characteristics, treatment and management characteristics, and poststroke clinical presentations.

\section{Primary outcomes}

Poor functional outcomes were defined as a modified Rankin Scale score of $>2$ in 9 studies and as a Barthel Index score of $<20$ in the other 2 .
Figure RR of poor functional outcomes 5 years after stroke in 7 studies

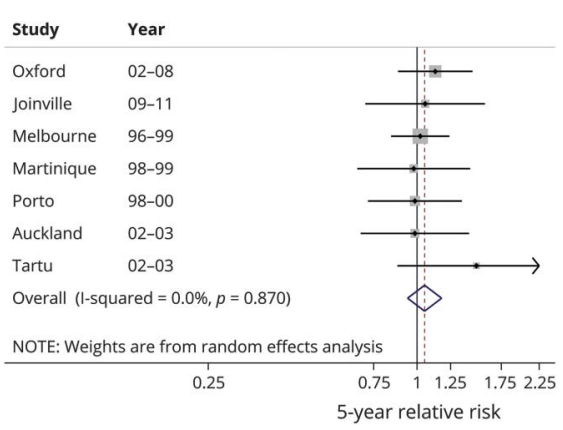

\section{Main results and the role of chance}

Relative to men, women experienced worse functional outcomes at 1 year after stroke $\left(\mathrm{RR}_{\text {unadjusted }} 1.32\right.$; 95\% confidence interval [CI], 1.18-1.48) and 5 years ( $\left.\mathrm{RR}_{\text {unadjusted }} 1.31 ; 95 \% \mathrm{CI}, 1.16-1.47\right)$. However, adjustment for age, prestroke dependency, and stroke severity attenuated the differences after 1 year $\left(\mathrm{RR}_{\text {adjusted }}, 1.08 ; 95 \% \mathrm{CI}\right.$, $0.97-1.20)$ and 5 years ( $\mathrm{RR}_{\text {adjusted }} 1.05$; $\left.95 \% \mathrm{CI}, 0.94-1.18\right)$.

\section{Bias, confounding, and other reasons for caution}

Variability in covariate measurements might have biased the RR adjustments.

\section{Generalizability to other populations}

The use of studies from multiple continents favors the generalizability of the results to other populations.

\section{Study funding/potential competing interests}

This study was funded by government research councils and medical research foundations in Australia, New Zealand, Brazil, and the UK. The authors report no competing interests. Go to Neurology.org/N for full disclosures. 


\section{Neurology}

\section{Factors contributing to sex differences in functional outcomes and participation after stroke}

Hoang T. Phan, Christopher L. Blizzard, Mathew J. Reeves, et al.

Neurology 2018;90;e1945-e1953 Published Online before print April 27, 2018

DOI 10.1212/WNL.0000000000005602

This information is current as of April 27, 2018

\section{Updated Information \&} Services

References

Citations

Subspecialty Collections

Permissions \& Licensing

Reprints including high resolution figures, can be found at: http://n.neurology.org/content/90/22/e1945.full

This article cites 37 articles, 16 of which you can access for free at: http://n.neurology.org/content/90/22/e1945.full\#ref-list-1

This article has been cited by 1 HighWire-hosted articles: http://n.neurology.org/content/90/22/e1945.full\#\#otherarticles

This article, along with others on similar topics, appears in the following collection(s):

All Cerebrovascular disease/Stroke

http://n.neurology.org/cgi/collection/all_cerebrovascular_disease_strok $\mathrm{e}$

Cohort studies

http://n.neurology.org/cgi/collection/cohort_studies

Risk factors in epidemiology

http://n.neurology.org/cgi/collection/risk_factors_in_epidemiology

Information about reproducing this article in parts (figures,tables) or in its entirety can be found online at:

http://www.neurology.org/about/about_the_journal\#permissions

Information about ordering reprints can be found online:

http://n.neurology.org/subscribers/advertise

Neurology ${ }^{\circledR}$ is the official journal of the American Academy of Neurology. Published continuously since 1951, it is now a weekly with 48 issues per year. Copyright (O 2018 American Academy of Neurology. All rights reserved. Print ISSN: 0028-3878. Online ISSN: 1526-632X.

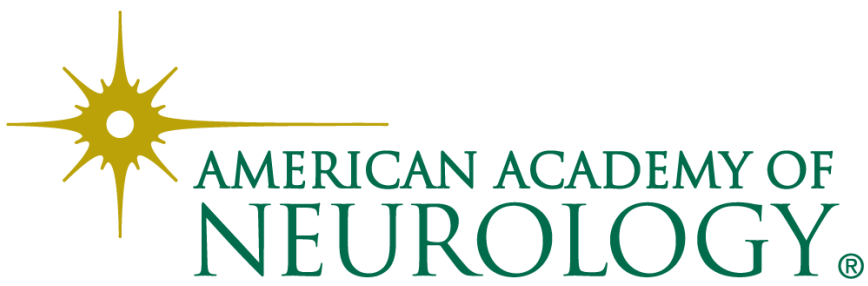

